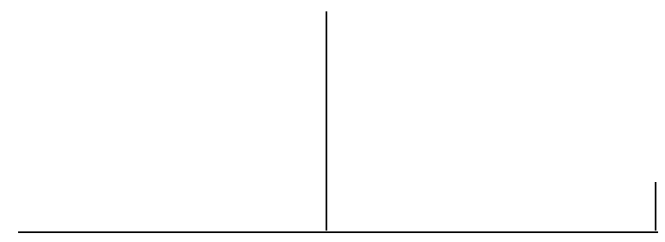

Rev. Latinoam. Psicopat. Fund., São Paulo, v. 14, n. 4, p. 611-626, dezembro 2011

\title{
A crítica psicanalítica do DSM-IV - breve história do casamento psicopatológico entre psicanálise e psiquiatria
}

Faz-se uma análise crítica da utilização do DSM na clínica psiquiátrica a partir da psicanálise. Discutem-se as bases e o estado atual de relações entre a psiquiatria dita "biológica" e a psicanálise na pesquisa em psicopatologia. O objetivo é mostrar os profundos compromissos e as zonas de resistência entre a psicopatologia psicanalítica e a psiquiatria biológica. Demonstra-se que o DSM é o sintoma maior da supressão individual dos múltiplos discursos sobre o mal-estar.

Palavras-chave: Psicanálise, psicopatologia, diagnóstico, psiquiatria 


\section{Introdução}

Neste artigo fazemos uma análise crítica da utilização do Manual Diagnóstico e Estatístico de Transtornos Mentais (DSM) na clínica psiquiátrica a partir da perspectiva da psicanálise. Discutimos as bases e o estado atual de relações entre a psiquiatria dita "biológica" e a psicanálise no plano da pesquisa em psicopatologia. Nossa reconstrução histórica objetiva mostrar os profundos compromissos e as zonas de resistência entre as duas formas de psicopatologia. Nos interessamos pelo papel que a psicanálise pode assumir no contexto contemporâneo da psicopatologia. Uma tentativa de situar o discurso psicanalítico no contexto atual de uma hegemonia do DSM na psiquiatria, escapando à visada mais intuitiva que a relação de externalidade atual faz presumir.

A execução dessa proposta é fundamental para que as disciplinas metodologicamente mais distantes desse sistema de classificação, como a psicanálise, possam modular uma linha de debate e crítica ao DSM. Por vezes, este é empregado como pretexto para uma "língua comum", a partir da qual as discussões diagnósticas e de tratamento se efetivariam. Baseados na reconstrução histórica das relações entre psicanálise e nos DSM, pretendemos demonstrar que esta base comum é antiga e serve para a homogeneização e silenciamento das controvérsias e divergências "internas", quer à psicanálise ou à psiquiatria. A fragilidade que o relativismo supostamente traria é escamoteada em prol de uma unidade gerada por oposição. Inversamente, a antiga e profícua dissensão entre escolas psiquiátricas europeias e americanas, e no interior de cada qual, ficaria suspensa por meio deste artifício fundamental, deste basic english proposto pelo $\mathrm{DSM}^{1}$ e por Ogden e Richards. Notemos a afinidade entre o

1. O basic english era uma língua reduzida, proposta por Ogden e Richards. Eles são autores de The meaning of meanin, que está entre as propostas de uma filosofia das formas simbólicas que permitiria reduzir o mal-entendido e favorecer a rapidez, coerência e consistência da comunicação (Ogden; Richards, 1923). 
projeto desses linguistas e as aspirações que comandaram a origem e o desenvolvimento histórico do DSM: desambiguação de termos semiológicos e diagnósticos, orientação para o consenso prático, função de arbitragem, aspiração metalinguística.

O objetivo deste artigo é mostrar que o DSM como figura histórica de compromisso - menos do que representar o pomo da discórdia, choque entre duas civilizações (psiquiátrica e psicanalítica) - é o sintoma maior da supressão individual dos múltiplos discursos sobre o mal-estar, o sofrimento e o sintoma, ou seja, do choque "intercivilizações".

\section{O DSM-I (1918) e a influência da psicanálise no pensamento de Adolf Meyer}

A necessidade de recolher informação estatística foi o impulso inicial para o desenvolvimento de uma classificação de transtornos mentais nos Estados Unidos. A primeira tentativa oficial foi o censo de 1840, que levou em conta a única oposição: idiotice ou insanidade. Quarenta anos mais tarde, o censo distinguiu entre sete categorias: mania, melancolia, monomania, paralisia, demência, alcoolismo. A partir destas, a Associação Psiquiátrica Americana (APA) e a Comissão Nacional de Higiene Mental desenvolveram um novo guia para os hospitais mentais, o Manual Estatístico para o Uso de Instituições de Insanos (DSM), que incluiu 22 diagnósticos.

O DSM-I teve grande influência do sistema diagnóstico de Meyer (1866-1950) com predomínio de categorias de extração psicodinâmica, ressaltando-se a oposição entre neurose e psicose. Opondo-se à noção de processo e às divisões propostas por Kraepelin na grande síntese psiquiátrica alemã, Meyer $^{2}$ centrou sua racionalidade diagnóstica em tipos de reação e no pressuposto sintético da história de vida e das moções determinantes das doenças mentais. O primeiro grupo é referido em torno do espectro que vai da ansiedade à depressão, com relativa preservação da ligação com a realidade. O segundo caracteriza-se pela presença de alucinações e delírios com perda substantiva da realidade (Wilson, 1993). Quadros de etiologia biológica e condições responsivas a contextos sociais específicos encontravam-se representados. $\mathrm{O}$ conjunto não refletia clara separação entre

2. A maior contribuição de Adolf Meyer à psiquiatria vem da insistência de que o paciente seria melhor compreendido se suas situações de vida fossem levadas em consideração. 


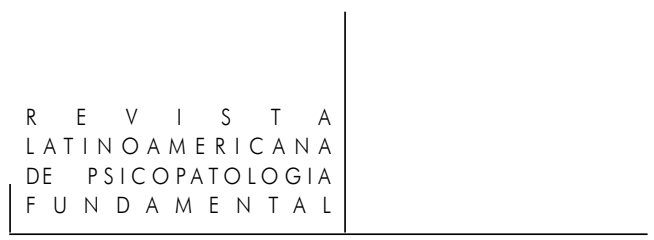

normal e patológico; a obra pretendia estabelecer um consenso terminológico entre os clínicos.

\section{O DSM-II (1952) e o compromisso diagnóstico entre psicanálise e psiquiatria}

O DSM-II evoluiu a partir dos sistemas de coleta de recenseamento e estatísticas de hospitais psiquiátricos e de um manual desenvolvido pelo Exército dos Estados Unidos com a finalidade de seleção e acompanhamento de recrutas e das vicissitudes surgidas no contexto da guerra. Na versão de 1952, o sistema amplia a classificação utilizada pelo exército desde 1918, de modo a uniformizar os critérios semiológicos da prática diagnóstica em torno de 180 distúrbios. Suas categorias são de extração psicodinâmica, ainda fortemente marcada pela oposição neurose e psicose de Meyer.

Embora a APA estivesse envolvida com a revisão da seção de transtorno mental da Classificação Internacional de Doenças (CID) - versão 8 em 1968 - decidiu também revisar o DSM. O termo "reação" foi abandonado, mas o "neurose" foi mantido. A versão II, assim como a anterior, refletia a predominância da psicodinâmica psiquiátrica, embora as perspectivas biológicas e conceitos do sistema de Kraepelin de classificação estivessem incluídos. Os sintomas não eram especificados com detalhes em distúrbios específicos. Muitos eram vistos como reflexos de grandes conflitos subjacentes ou reações inadequadas aos problemas da vida, enraizados em três grupos fundamentais: oposição entre neurose e psicose; oposição entre ansiedade ou depressão e alucinações ou delírios; oposição entre quadros largamente em contato com a realidade e quadros denotando significativa perda da realidade.

As três oposições eram contrabalançadas pela assimilação de teses biológicas e sociológicas que matizam a clareza do limite entre normalidade e anormalidade. Esta estratégia foi mal recebida.

\section{O DSM-III (1973-1974): novos eixos e o expurgo psicanalítico}

Entre 1952 e 1973 o DSM-II atrai a ira dos críticos que nele reconhecem uma síntese do compromisso entre a psiquiatria mais normativa e a psicanálise mais retrógrada. Casamento celebrado sob os auspícios de um cientificismo ideológico. A associação entre histeria e feminilidade ou homossexualidade e perversão é exemplo de que o manual representaria a realização institucional referendada pelo 


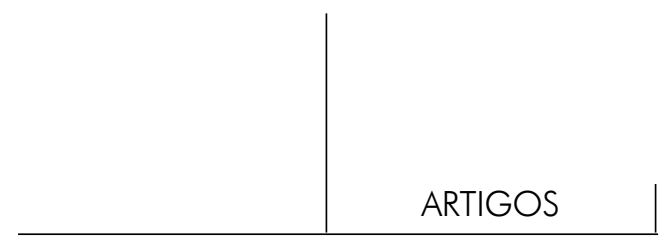

Estado e articulada aos seus dispositivos educacionais, jurídicos e de pesquisa para repressão política. A individualização e patologização de contradições sociais, a segregação de minorias e o controle e neutralização de resistências encontrariam, assim, um referendo psiquiátrico-psicanalítico.

Na sequência de polêmicas e protestos de críticos e ativistas em conferências anuais da APA e com o surgimento de novos dados de pesquisadores como Kinsey e Hooker, o DSM-II não figurou homossexualidade como uma categoria de desordem. Devido aos esforços do psiquiatra Robert Spitzer, o diagnóstico foi substituído pela categoria de "distúrbio de orientação sexual", atualmente: transtorno de identidade de gênero (GID). Pereira (2000) relata que no início da revisão do DSM II, surgiu o debate sobre manter ou não a homossexualidade como categoria diagnóstica específica.

Em 1970, ativistas gays invadiram o congresso da APA e protestaram contra a ideia do comportamento homossexual como intrinsecamente patológico. Os combates continuaram por anos. E, em 1973, a APA aceita que a homossexualidade não poderia ser considerada patológica. Assim, surge a categoria "homossexualidade egodistônica", reunindo sujeitos que vivenciam a homossexualidade de forma conflitiva, mas que gostariam de se ver livres dessa condição.

Em 1974, a decisão de criar uma nova revisão do DSM foi tomada e Spitzer teve o cargo de presidente da força-tarefa. Um dos objetivos da revisão foi melhorar a uniformidade e a validade do diagnóstico psiquiátrico. Outro era padronizar as práticas de diagnóstico dentro dos Estados Unidos e outros países. O estabelecimento de critérios também foi uma tentativa de facilitar o processo de regulamentação farmacêutica. O potencial de novas categorias de desordem foi estabelecido por consenso durante as reuniões da comissão. A proposta era uma base de categorização em inglês descritivo, em vez de suposições de etiologia ("neokraepelinismo").

Os pontos de vista psicodinâmicos e fisiológicos deram lugar a um modelo regulamentar ou legislativo. Um novo eixo "multiaxial" foi criado. O sistema tentou produzir uma imagem mais propícia para um recenseamento da população estatística, em vez de apenas um diagnóstico simples. Spitzer argumentou que transtornos mentais são subconjuntos das desordens médicas. A força-tarefa decidiu que cada desordem mental é concebida como uma síndrome clinicamente significativa, comportamental ou psicológica.

Assim surgiu o DSM-III, com a introdução de novas categorias de desordens. A controvérsia surgiu em relação à supressão do conceito de "neurose", um dos princípios da teoria psicanalítica e uma das justificações para o alcance dessa condição pela psicoterapia. Para os reformadores do DSM-III, essa noção tornara-se vaga e não científica e passou por sério perigo de não ser aprovado pelo Conselho de Administração da APA, a menos que "neurose" fosse incluída em al- 


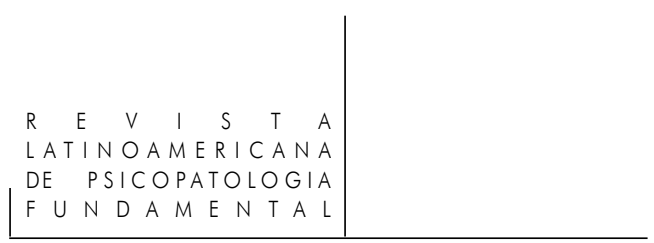

guma incapacidade. Um compromisso político de reutilização do termo foi assumido e inserindo entre parênteses, em alguns casos, depois da palavra "desordem" (disorder). O diagnóstico de homossexualidade egodistônico substituiu a categoria de "distúrbio de orientação sexual".

Finalmente publicado em 1980, o DSM-III tem sido considerado uma profunda transformação da psiquiatria. Propondo-se como um sistema classificatório ateórico e operacional das grandes síndromes psiquiátricas, esse manual modificou a concepção de pesquisa e da prática psiquiátrica, pois a psiquiatria teria disponível um sistema de diagnóstico preciso do ponto de vista descritivo-terminológico e passível de servir de apoio para a pesquisa empírico-experimental.

Segundo Pereira (2000), a partir do DSM-III, os diagnósticos seriam considerados como instrumentos convencionais, dispensando qualquer referência ontológica. A única exigência seria a concordância no plano descritivo. O DSM-III admite, pela última vez, o emprego da neurose como categoria clínica. Os contextos e variantes sociais são reduzidos a "síndromes culturais específicas" ou distribuídos por um entendimento bastante limitado do campo social na determinação, expressão e caracterização dos transtornos mentais. ${ }^{3}$

\section{O DSM-IV (1994-2000): a dissolução da psicopatologia}

Listando 297 desordens em 886 páginas, em 1994 o DSM-IV foi publicado. Um comitê de direção de 27 pessoas foi introduzido, incluindo quatro psicólogos. A grande mudança foi a inclusão de um critério de significância clínica para quase metade de todas as categorias que possuíam sintomas e causavam sofrimento clinicamente significativo ou prejuízo no funcionamento social, ocupacional ou outras áreas importantes de funcionamento. Em 2000, o DSM-IV foi revisado (DSM-IV-R). Atualmente, o DSM-V está em discussão, planejamento e preparação para publicação em 2012.

Portanto, nos vinte anos que separam o DSM-III do IV, rompeu-se a tradição, em vigor desde Pinel, em que a caracterização das formas de sofrimento, alienação ou patologia mental fazia-se acompanhar da fundamentação ou da crítica filosófica. Rompeu-se não só o casamento entre psicanálise e psiquiatria, celebrado sob os auspícios de figuras de compromisso, como a psiquiatria

3. Segundo Mayes e Horwitz (2005), o manual é uma referência internacional aceita na maior parte dos países do Ocidente, utilizado massivamente pelos sistemas de saúde pública, convênios médicos e centros de pesquisa psiquiátrica e farmacêutica. 
psicodinâmica, mas também certa maneira de fundamentar e fazer psicopatologia. Ou seja, em vez de progredir pela ambiguação de línguas concorrentes, recorreu-se à unidade desambiguadora da norma. ${ }^{4}$

A ruptura não se dá no nível das teses que se opõem, mas do próprio princípio pelos quais as teses serão julgadas. Trata-se de uma mutação da própria razão diagnóstica e não de um de seus movimentos de contradição interna. Afirmar que a ruptura entre psiquiatria biológica e psicanálise se dá em função de critérios de cientificidade, mais ou menos positivistas, por exemplo, é jogar pelas regras de um jogo ultrapassado. O importante é entender como as regras daquilo que estamos dispostos a contar como racional, no dispositivo social que é o diagnóstico, foram alteradas, dispensando a concorrência de paradigmas.

Recuemos para que o argumento fique mais claro. Entre o DSM-III e o DSMIV rompeu-se a antiga prática ou o consenso tácito, que fez a psicopatologia depender de duas estratégias de autojustificação: a antropologia filosófica e a filosofia da história. Em poucas palavras, toda psicopatologia deve prestar contas e entabular uma resposta para:

a) O problema da "universalidade das formas do patológico" - uma explicação para a existência de regularidades clínicas que permanecem no tempo e no espaço, apesar de alterações e modulações expressivas e funcionais. É no interior desse problema que vemos emergir a posição biológica ou organicista, que advogará a universalidade biológica das modalidades do patológico baseada em perturbações genéticas, endócrinas, neuroquímicas, anatômicas. Nasce aqui também a posição contrária, que advogará a fundamentação social da universalidade das formas do patológico, remetendo-a a contradições derivadas do que há de universal entre ou nas culturas, por exemplo, estruturas familiares, funções de personalidade, gramáticas simbólicas. Ambas as posições devem dar conta ainda de um problema comum: explicar que tipo de relação está prevista entre as formas simbólicas universais e os tipos particulares de expressão, manifestação ou apresentação de sintomas. Esses casos seriam particularidades de tipos universais? Subconjuntos de conjuntos maiores? Qual lógica preside a relação entre elementos e conjuntos e entre conjuntos?

4. A grande oposição não se dá entre fundamentação biológica ou psicológica. Basta lembrar de figuras teóricas como a neuropsicanálise ou como a etnopsiquiatria, que invertem facilmente esta oposição, ou ainda figuras atitudinais de linhagem biopsicossocial, para verificar que o que está em questão, no fundo, é a própria inanidade das atitudes fundacionistas em relação aos procedimentos práticos e de autonomização jurídica das regras de gestão da saúde mental.

Rev. Latinoam. Psicopat. Fund., São Paulo, v. 14, n. 4, p. 611-626, dezembro 2011 


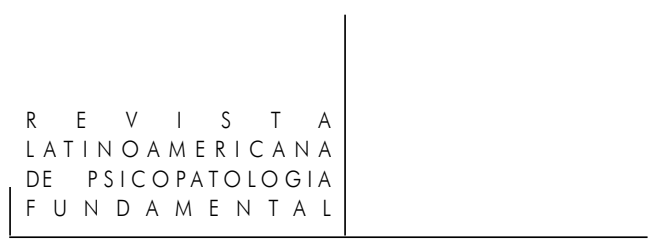

b) O problema da "evolução do patológico" em relação com sua própria historicidade, transformação e reatividade às circunstâncias que se impõem a alguém acometido por uma afecção dessa natureza. $O$ fato elementar nesse caso diz respeito à natureza transformativa ou evolutiva do sintoma. Transformação que justifica e torna possíveis as tentativas de tratamento, cura ou remissão. A lógica transformativa exige que se considerem modos de relação entre o sujeito e seu sintoma, tipos de reação da personalidade com o processo mórbido, efeitos intersubjetivos de adaptação ou distonia frente a uma determinada patologia. Surgem duas posições. Há aqueles que advogam a natureza essencial, orientada e dirigida dessa transformação, seja ela baseada em argumentos de fato naturalistas (como uma psicologia do desenvolvimento) ou ainda em argumentos derivados de uma ontologia humanista, pré ou pós-metafísica. Em oposição, há aqueles que se sugerem a relativa indistinção entre a história do sujeito e a de seus sintomas, como os que se apoiam na noção de estrutura, mas também nos funcionalistas de todo gênero.

Diagnóstico diferencial para o primeiro problema e evolutivo para o segundo. Etiologia como causa no primeiro e como determinação no segundo. Semiologia como língua no primeiro e como fala no segundo. O recurso à filosofia marca historicamente a psicopatologia na medida em que esta é tomada como solo de colocação e de pré-encaminhamento das duas questões e principalmente da solução articulada das duas exigências epistemológicas. ${ }^{5}$ A partir de meados do século XX, esse sistema de correspondências psiquiátrico-filosófico se deslocou de maneira a incluir a psicanálise. Isso se mostra inicialmente no modelo proposto por Bleuler e depois na figura de compromisso, um tanto ambígua quanto a sua definição exata, conhecida como psiquiatria psicodinâmica.

As implicações filosóficas, éticas e epistemológicas do DSM, não são assumidas explicitamente e o centro da problemática é deslocado para o campo genérico da fundamentação das ciências biológicas. O que nos interessa é esse rompimento do nexo com os discursos psicanalítico e social, que faziam a patologia mental depender dos modos de subjetivação e socialização em curso, em um dado regime de racionalidade. Assim, é bastante plausível que tais modos de subjetivação e socialização encontrem-se ainda presentes nas categorias psiquiátricas, pois sua formação histórica acusa essa dependência. Porém, isso se tor-

5. Isso se mostra na influência que Pinel exerceu sobre o pensamento hegeliano, na importância de Kant para a formação da psiquiatria clássica alemã (Kraepelin), do associacionismo inglês na psiquiatria de Griesinger, ou do positivismo comteano para a psiquiatria clássica francesa (Esquirol, Morel) ou ainda a presença de Husserl na psiquiatria de Karl Jaspers (Berrios, 1996). 
nou invisível e apagado da prática diagnóstica corrente ou das razões que a justificam.

\section{DSM-V: qual psicanálise para qual psiquiatria?}

Sabemos que o próprio termo psicopatologia é carregado de ambiguidades. Trata-se de uma terminologia fortemente associada às raízes psiquiátricas. Tal termo evoca uma disciplina que trata da natureza da doença mental, suas causas, mudanças estruturais e funcionais ligadas a ela e suas formas de manifestação. Em uma acepção bastante genérica, a psicopatologia pode ser considerada como um conjunto de conhecimentos acerca do adoecimento mental do ser humano. Jaspers chamava atenção para as ambiguidades inerentes à pesquisa em psicopatologia:

[...] tanto na psicologia quanto na psicopatologia talvez não se possa afirmar nada ou quase nada que não seja, de alguma maneira, contestado. Por isso se alguém pretende estabelecer a razão de suas afirmações e descobertas e elevá-las acima da onda de intuições psicológicas diárias, terá também de empreender reflexões metodológicas. (Jaspers, 1913, p. 16)

Lembramos que o DSM foi constituído a partir de uma perspectiva ateórica e operacional. O DSM tem como objetivo constituir-se num sistema de classificação sobre dados diretamente observáveis, sem recorrer a sistemas teóricos. Recorremos a Goldberg, integrante da comissão responsável pelas novas edições do DSM, recentemente entrevistado pela Folha de S. Paulo. Ele relata que as depressões unipolares simples, os estados de ansiedade, os transtornos de medo e os de ordem somática são exemplos de sintomas que possuem "variações pequenas que distinguem um do outro". Frente às dificuldades diagnósticas devido às “variações pequenas”, Goldberg (2009) propõe: “... você só pode fazer diagnósticos ignorando alguns sintomas, então será melhor se os médicos apenas descrevessem os sintomas gerais que as pessoas têm nesse grupo de transtornos [emocionais]".

A descrição minuciosa, fina e precisa dos sinais e sintomas dos transtornos mentais, constitui a base semiológica de um processo investigativo em busca da etiologia. Pereira (1998) nos adverte que a ideia de que as alterações mentais teriam um estatuto de patologia se formou gradativamente em psiquiatria, não estando totalmente clara nas hipóteses de seus precursores.

Kraepelin foi o grande sistematizador da psicopatologia descritiva. Ele radicaliza a concepção falretiana de entidade mórbida, consolidando de forma definitiva a vocação nosológica da psicopatologia. Bercherie (1989) lembra que em

Rev. Latinoam. Psicopat. Fund., São Paulo, v. 14, n. 4, p. 611-626, dezembro 2011 


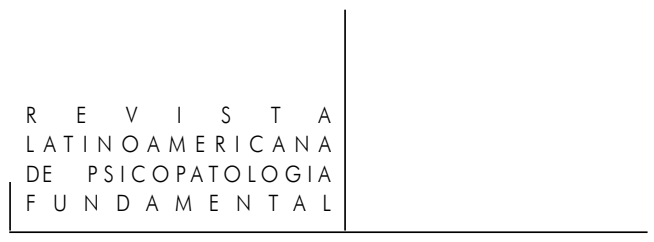

trinta anos o Manual de Psiquiatria de Emil Kraepelin conheceu oito edições e não houve uma só edição sem modificações nosológicas. Do ponto de vista kraepeliano, trata-se de discernir, sob as bases clínicas, as diversas formas do adoecimento mental, as quais teriam o mesmo estatuto das doenças físicas tratadas pela medicina.

Diante das considerações acerca da semiologia e do trabalho de Kraepelin, nos parece que a declaração de Goldberg explicita uma prática clínica que prescinde da descrição fina da entidade mórbida e consequentemente abdica da busca pela etiologia das patologias.

Jaspers (1913) funda a psicopatologia geral como uma disciplina estritamente fenomenológica. Ele não enfatiza a noção de entidade mórbida e passa a delimitar o campo da psicopatologia não mais como o da descrição de sinais e sintomas das diferentes patologias mentais, mas como o da busca de "intuições categoriais" oriundas do contato clínico com o doente mental, na esperança de poder traduzir a experiência efetivamente vivida (Erlebnis) pelo paciente em seu estado de padecimento psíquico. Em seu tratado Psicopatologia geral, esse autor afirma que o objeto da psicopatologia é o fenômeno consciente e ressalta seu interesse em conhecer as realidades psíquicas e as condições e causas das quais dependem o nexo que estrutura as relações.

O DSM procura constituir-se num sistema classificatório fidedigno dos padecimentos psíquicos e não possui a pretensão de ser uma psicopatologia. Sua racionalidade está organizada em torno da busca de categorias confiáveis, provisórias e operacionais que permitam a superação de mal-entendidos terminológicos no terreno da psicopatologia. Seu critério de objetivo está alicerçado na descrição formal do plano empírico dos fatos clínicos.

Porém, Pereira (1996) aponta críticas ao caráter falsamente ateórico do DSM e de adesão implícita às teses empiristas. O "compromisso prático" do DSM obriga pesquisadores a abandonar os conceitos teóricos próprios de seus campos específicos de saber com uma consequência direta: a incapacidade do progresso das disciplinas científicas que compõem o campo da psicopatologia devido à inaptidão das mesmas por constituírem teórica e formalmente seus objetos e métodos próprios. Os compromissos com o pragmatismo certamente resultam em um enfraquecimento de cada ciência.

\section{A psicanálise e o DSM: um enfoque crítico}

Apesar de tais críticas, a delimitação das categorias mostrou-se particularmente conveniente para disciplinas que operam com uma metodologia empírico- 


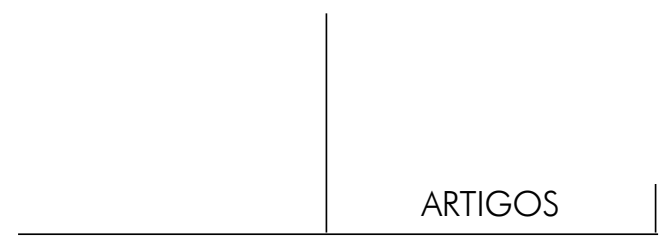

-experimental em suas abordagens do sofrimento psíquico. Notamos um uso intenso do DSM na epidemiologia, nas neurociências e no planejamento de uso de verbas públicas em programas de saúde mental.

O uso do DSM nas políticas públicas de saúde mental é baseado no fato que para organizar de forma eficiente os investimentos em saúde pública (incluindo-se a saúde mental), o gestor deve saber quais são as entidades clínicas mais frequentes e prevalentes em certa comunidade e conhecer a real eficácia das diferentes modalidades terapêuticas disponíveis. Segundo Pereira (1998), temos aqui uma perspectiva que considera a medicina uma forma de intervenção concreta na ordem da vida e das instituições sociais. O sofrimento mental passa a ser encarado como questão de saúde pública. ${ }^{6}$ No contexto contemporâneo, balizar a prática clínica pela eficácia passa a ser um ideal ético. Surge então a necessidade de se demonstrar a eficácia de uma prática que possa ser reconhecida no plano oficial

Figueiredo e Tenório (2002) questionam a eficácia do uso do DSM-IV como instrumento da diagnóstica em psiquiatria. A partir de um caso clínico, os pesquisadores fizeram um estudo comparado entre o material da anamnese da paciente e o da entrevista psicanalítica que permitiu a emergência do sujeito a partir de sua fala. Demonstrou-se que a diferença da lógica diagnóstica do DSM-IV e da psicanálise traz importantes consequências para a condução do tratamento, pois o diagnóstico decorre de uma definição prévia implícita ou explicita sobre a função de uma terapêutica, ele também influencia os alcances do tratamento.

Afirmamos anteriormente (Dunker, 2010) que existe uma desarticulação entre história e estrutura na racionalidade diagnóstica atual. Na psiquiatria baseada no DSM-IV permanece uma grande oposição entre transtornos clínicos (eixo I) e de personalidade (eixo II). O eixo I busca descrever os sintomas da pessoa. O eixo II almeja descrever sua personalidade, ou seja, como ela é. A psiquiatria almejada pelo DSM não pretende constituir-se como uma psicopatologia estrutural, pois as classes não são definidas por regras de formação e as ordens não se conectam com lógicas causais. Daí, temos diversas dificuldades classificatórias tais como a possibilidade de dois pacientes diagnosticados com Transtorno Obsessivo Compulsivo não possuírem nenhum sintoma em comum.

Retomamos a afirmação de que a utilidade diagnóstica do DSM seria intervir em cada episódio de aparecimento do sintoma. A perspectiva de basear a prá-

6. Foucault (2008) considera o liberalismo como a moldura da biopolítica. Sua análise evidencia o papel paradoxal da sociedade em relação ao governo: este tende a se autolimitar, mas também é alvo de uma intervenção governamental permanente para produzir, garantir e multiplicar as liberdades necessárias ao liberalismo econômico.

Rev. Latinoam. Psicopat. Fund., São Paulo, v. 14, n. 4, p. 611-626, dezembro 2011 


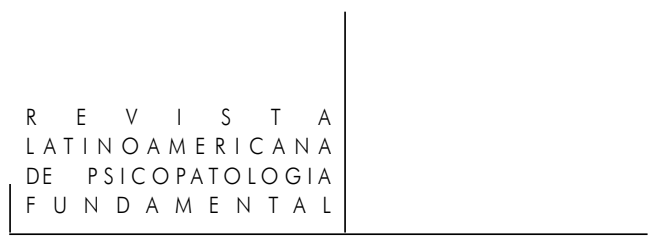

tica clínica pela eficácia leva a hipervalorização da chamada "Medicina Baseada em Evidências" (MBE). A noção de eficácia na MBE está associada ao tratamento em condições de mundo ideal, ou seja, a supressão dos sintomas. A própria apresentação do DSM-IV-TR (casos clínicos) adota de forma explicita essa tendência.

Pereira (1998) levanta a hipótese que a hipervalorização da MBE é uma forma de proteger os clínicos de questionamentos, sobretudo envolvendo questões jurídicas, de suas condutas com pacientes. Teríamos, assim, uma padronização normativa do que se está cientificamente legitimado a executar na condição de clínico.

Atualmente, a MBE tende a substituir a clínica pela epidemiologia, apontando a penúria da prática clínica, do terapeuta dedicado à arte de curar. Temos um colapso das práticas clínicas como forma de intermediação entre o conhecimento geral das disciplinas clínicas e o sujeito que sofre. Tais consequências da normatização das práticas clínicas causam repercussões consideráveis sobre todas as práticas fundadas na clínica.

Sobre esse aspecto, Dunker (2009), ao abordar o tratamento da depressão, ressalta que as divergências entre a psicanálise e a psiquiatria estão mal focadas. Para ele não há nada de contrário à psicanálise na tese de que a depressão é um desequilíbrio dos mecanismos de produção e recaptação de determinados neurotransmissores. A questão relevante está quando se afirma que a concorrência entre desequilíbrio neuroquímico e depressão não autoriza atribuir a tal desequilíbrio uma função causal. Assim, temos algumas perguntas intrigantes: ficamos tristes porque há menos serotonina, ou há menos serotonina porque ficamos tristes? O que causa a depressão é a diminuição da recaptação da serotonina no interior dos neurônios, ou essa é apenas uma descrição do processo?

Distintamente, Goldenberg (2009) propõe que os psicanalistas se interroguem sobre os motivos que os fazem perder espaço na sociedade para fazer chegar aos cidadãos a sua própria mensagem de modo invertido. $\mathrm{O}$ autor defende a ideia de que os psicanalistas estão negligenciando a atualidade da cultura em que vivem e que, muitos deles, só conhecem a atualidade de Freud e Lacan, transformando seus discursos em uma paródia.

Em ambas as perspectivas, um ponto de convergência: seja na crítica da cultura ou no diálogo com as neurociências, a psicanálise tem uma contribuição específica a dar, na medida em que permite uma abordagem racional do subjetivo, do singular e dos aspectos irredutíveis a grandes leis gerais sobre o sofrimento humano. Essas dimensões surgem em destaque quando passamos do plano das definições operacionais do sistema DSM para o plano concreto da prática clínico-terapêutica.

Rev. Latinoam. Psicopat. Fund., São Paulo, v. 14, n. 4, p. 611-626, dezembro 2011 
Dunker (2009) nos apresenta um argumento plausível sobre o uso exclusivo de medicamentos como forma de tratamento. Para ele, todo sintoma exprime um trabalho subjetivo. Além de um problema, exprime uma possível solução criada pelo paciente.

Todo medicamento só é eficaz porque realiza "por outras vias" um trabalho ou função que o organismo ou o sujeito pode fazer em condições normais. Ao introduzir o medicamento sem fornecer meios para que o sujeito recupere a possibilidade de realizar esse trabalho, produzimos uma espécie de "efeito colateral", uma "atrofia" das já debilitadas funções psicológicas [...] (p. 59-60)

Tais considerações parecem encontrar eco em Goldenberg (2009): o DSM não captura os tipos de doença mental senão os cria pelo prestígio do instrumento científico ou de quem dele se serve.

Assim, encontramos a pertinência das boas descrições psiquiátricas e psicanalíticas que são elaboradas com vistas a estratégias de intervenção e transformação. Se fossem simplesmente o neutro reflexo das coisas como tais, não seriam descrições de sujeitos. O diagnóstico em psicanálise além de ser estrutural é também sob transferência, o que exige do analista um trabalho de produzir certa fala que possa indicar algo da posição do sujeito na fantasia. Falamos de um endereçamento da fala, de uma ultrapassagem dos fenômenos que nos permite formular um diagnóstico como função terapêutica e concomitantemente nos afasta das caricaturas engendradas pelos manuais como padrões de sofrimento psíquico.

\section{Referências}

BerRIos, G.E. The History of Mental Symptoms. Cambridge: UK, 1996.

DunKer, C. I. L. Razão diagnóstica e psicopatologia psicanalítica. São Paulo, 2010. 28 p. Mimeografado.

. O urso-polar e as baleias. As divergências entre a psicanálise e a psiquiatria estão mal focadas. Revista Cult, São Paulo, ano XII, n. 140, p. 59-62, 2009.

Figueiredo, A. C.; Tenório, F. O diagnóstico em psiquiatria e psicanálise. Revista Latinoamericana de Psicopatologia Fundamental, São Paulo, ano V, n. 1, p. 29-43, mar. 2002.

Goldberg, D. Criar doenças mentais só atrapalha tratamento. Folha de S. Paulo, 17 dez.2009.

Goldenberg, R. O DSM-IV e nós. Revista Trivium. Estudos interdisciplinares em psicanálise e cultura, Rio de Janeiro, ano I, n. 1, p. 34-40, 2009.

Rev. Latinoam. Psicopat. Fund., São Paulo, v. 14, n. 4, p. 611-626, dezembro 2011 
JASPERS, K. (1913). Psicopatologia geral. Psicologia compreensiva, explicativa, fenomenológica. Rio de Janeiro: Atheneu, 1987.

MAYES, R.; HoRwitz, A.V. (2005) DSM-III and the revolution in the classification of mental illness. J Hist Behav Sci, n. 41, v. 3, p. 249-67, 2005.

Ogden, C.K.; Richards, I.A. (1923). The Meaning of Meaning: a study of the influence of language upon thought and of the science of symbolism. San Diego: Harcourt, Brace Jovanovich, 1989.

Pereira, M.E.C. O DSM-IV e o objeto da psicopatologia ou psicopatologia para $q u \hat{e}$ ? Disponível em: <www.estadosgerais.org/historia/98-dsm-.shtml>. Acesso: em 16 out. 2009.

. A paixão nos tempos do DSM: sobre o recorte operacional do campo da psicopatologia. In: Pacheco Filho, R. et al. Ciência, Pesquisa, Representação em Psicanálise. São Paulo: Educ/Casa do Psicólogo, 2000. p. 119-152.

. Questões preliminares para um debate entre a psicanálise e a psiquiatria no campo da psicopatologia. In: Couto, L.F.S. Pesquisa em psicanálise. Belo Horizonte: SEGRAC, 1996. p. 43-54.

Roudinesco, E. Por que a psicanálise? Rio de Janeiro: Jorge Zahar, 2000.

Spitzer, R. et al. Casos clínicos. Porto Alegre: Artmed, 2008.

WILSON, M. DSM-III and the transformation of American psychiatry: a history. Am J Psychiatry., n. 150, v. 3, p. 399-410, Mar. 1993.

\section{Resumos}

(Psychoanalytic critique of the DSM-IV - a short history of the pathological marriage between psychoanalysis and psychiatry)

We discuss here the foundations and the current state of relationships between what is known as "organic" psychiatry and psychoanalysis in research on psychopathology. The aim is to show the intense involvement as well as areas of resistance between psychoanalytic psychopathology and biological psychiatry. It is argued here that the DSM is the most serious symptom of the individual suppression of the multiple discourses on malaise.

Keywords: Psychoanalysis, psychopathology, diagnosis, psychiatry

(La critique psychanalytique du DSM-IV - bref historique du mariage psychopathologique entre la psychanalyse et psychiatrie)

Cet article présente une analyse critique de l'utilisation du DSM en clinique

Rev. Latinoam. Psicopat. Fund., São Paulo, v. 14, n. 4, p. 611-626, dezembro 2011 


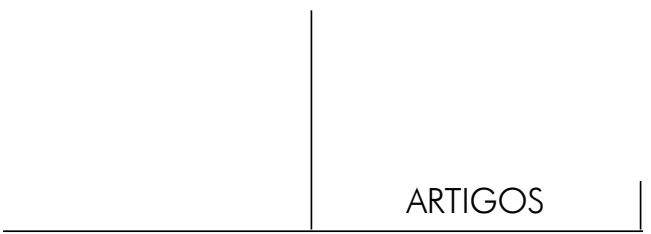

psychiatrique à partir de la psychanalyse. Nous discutons les bases et l'état actuel des rapports entre la psychiatrie dite "biologique" et la psychanalyse dans la recherche en psychopathologie. Notre but est de montrer les profonds compromis et les zones de résistance entre la psychopathologie psychanalytique et la psychiatrie biologique. Nous démontrons que le DSM est le symptôme majeur de la suppression individuelle des multiples discours sur le malaise.

Mots clés: Psychanalyse, psychopathologie, diagnostic, psychiatrie

(La crítica psicoanalítica del DSM-IV - breve historia del matrimonio psicopatológico entre el psicoanálisis y la psiquiatria)

Se realiza un análisis crítico de la utilización del DSM en la clínica psiquiatrica desde el psicoanálisis. Se discuten las bases y el estado actual de las relaciones entre la psiquiatría llamada "biológica" y el psicoanálisis en la investigación de la psicopatología. El objetivo es mostrar el profundo compromiso y las zonas de resistencia en la psicopatología psicoanalítica y la psiquiatría biológica. Se demuestra que el DSM es el mayor síntoma de la supresión individual de los múltipos discursos sobre el malestar.

Palabras clave: Psicoanálisis, psicopatología, diagnóstico, psiquiatria

Citação/Citation: Dunker, C.I.L.; KyrILlos Neto, F. A crítica psicanalítica do DSM-IV: breve história do casamento psicopatológico entre psicanálise e psiquiatria. Revista Latinoamericana de Psicopatologia Fundamental, São Paulo, v. 14, n. 4, p. 611-626, z.2011.

Editor do artigo/Editor: Prof. Dr. Manoel Tosta Berlinck

Recebido/Received: 23.4.2010 / 4.23.2010 Aceito/Accepted: 25.7.2010 / 7.25.2010

Copyright: (C) 2009 Associação Universitária de Pesquisa em Psicopatologia Fundamental/ University Association for Research in Fundamental Psychopathology. Este é um artigo de livre acesso, que permite uso irrestrito, distribuição e reprodução em qualquer meio, desde que o autor e a fonte sejam citados/This is an open-access article, which permits unrestricted use, distribution, and reproduction in any medium, provided the original author and source are credited.

Rev. Latinoam. Psicopat. Fund., São Paulo, v. 14, n. 4, p. 611-626, dezembro 2011 
Financiamento/Funding: Os autores declaram não ter sido financiados ou apoiados/The authors have no support or funding to report.

Conflito de interesses/Conflict of interest: Os autores declaram que não há conflito de interesses/The authors declare that has no conflict of interest.

\section{Christian Ingo Lenz Dunker}

Psicanalista; professor livre docente do Departamento de Psicologia Clínica do Instituto de Psicologia da Universidade de São Paulo - IPUSP (São Paulo, SP, Br).

Rua Abílio Soares, 932 - Paraíso

04005-003 São Paulo, SP, Brasil

e-mail: chrisdunker@usp.br

\section{Fuad Kyrillos Neto}

Doutor em Psicologia Social pela Pontifícia Universidade Católica de São Paulo - PUC-SP (São Paulo, SP, Br); integrante do Laboratório de Teoria Social, Filosofia e Psicanálise da Universidade de São Paulo - LATESFIP/USP (São Paulo, SP, Br)

Rua Silva Jardim, 51 - Centro

36201-004 Barbacena, MG, Brasil

e-mail: fuadneto@uol.com.br

Rev. Latinoam. Psicopat. Fund., São Paulo, v. 14, n. 4, p. 611-626, dezembro 2011 